\title{
Emotional Identity in the Process of Evaluation in Primary School Children. School and Family Expectations
}

Anca-Georgiana Simion, Cristian Stan 


\title{
Emotional Identity in the Process of Evaluation in Primary School Children. School and Family Expectations
}

\author{
Anca-Georgiana Simion ${ }^{a *}$, Cristian Stan ${ }^{b}$ \\ ${ }^{a, b}$ Faculty of Psychology and Educational Sciences, Babeș-Bolyai University, 7 Sindicatelor Street, Cluj-Napoca, 400029, Romania
}

*Corresponding author: ancasimion1@gmail.com

\section{Abstract}

\section{Keywords:}

evaluation, assessment, emotional identity, emotions, wellbeing, family expectations
School years have an important role in defining a person for the world he will live in. The influence that the school environment has on defining a person for the future is something that teachers and policy makers take into consideration when developing strategies for learning and equally important in the evaluation process. The evaluation process is an integral part of the education process and the connections between evaluation, assessment of learning and learning constitute a focal part of the educators. School performance is not solely a function of student's aptitude set, but also covers the optimal cognitive and affective-motivational recourses in relation to certain tasks. Emotional competence, along with the social competence is important in the development of positive relationships and emotionally feelings of security in creating a positive self image for young people. Young people with a positive self image will have a greater disposition to learning. For children learning about themselves happens within the context of their families and community and it includes all the type of relationships they forge with their peers, places and things in relation to the actions and responses from others. Experience is the one that shapes the emotional responses that children have in regards to all the things happening around them and inside them, at a self-understanding level. This paper aims to understand the way emotional identity of children helps them focus on the evaluation task in various contexts of every day school life.

Schuljahre spielen eine wichtige Rolle bei der Charakteriesierung einer Person für die Welt, in der sie lebt. Der Einfluss, den das schulische Umfeld auf die Charakteriesierung einer Person für die Zukunft hat, wird von Lehrern und politischen Entscheidungsträgern bei der Entwicklung von Lernstrategien berücksichtigt und ist gleichermaßen wichtig im Bewertungsprozess. Der Evaluierungsprozess ist ein wesentlicher Bestandteil des Bildungsprozesses, und die Zusammenhänge zwischen Evaluierung, Bewertung des Lernens und Lernen bilden einen Schwerpunkt der Pädagogen. Die schulische Leistung hängt nicht nur von der Eignung des Schülers ab, sondern deckt auch die optimalen kognitiven und affektiv-motivationalen Ressourcen in Bezug auf bestimmte Aufgaben ab. Emotionale Kompetenz ist neben der sozialen Kompetenz wichtig für die Entwicklung positiver Beziehungen und emotionaler Sicherheitsgefühle, um ein positives Selbstbild für junge Menschen zu schaffen. Junge Menschen mit einem positiven Selbstbild werden eine größere Neigung zum Lernen haben. Für Kinder geschieht das Lernen über sich selbst im Kontext ihrer Familien und ihrer Gemeinschaft und umfasst alle Arten von Beziehungen, die sie zu Gleichaltrigen, Orten und Dingen in Bezug auf die Handlungen und Reaktionen anderer knüpfen. Erfahrung ist diejenige, die die emotionalen Reaktionen der Kinder in Bezug auf all die Dinge, die um sie herum und in ihnen geschehen, auf einer Ebene des Selbstverständnisses prägt. Dieses Schriftstück soll zum Verständnis bringen, wie die emotionale Identität von Kindern ihnen hilft, sich auf die Bewertungsaufgabe in verschiedenen Kontexten des täglichen Schullebens zu konzentrieren.

\section{Introduction: Emotional identity and the evaluation process}

Relationships are the foundation for the construction of identity which responds to existential questions - 'who I am', 'where I belong' and 'what is my influence?'. Experiences in early life have a capacity for providing a set of mechanisms built to encourage the development of moral growth at a later age (Thompson, 2017). The author also makes a valid point regarding the existence of milestones in the child life that are a precursor for emotional understanding and relational experience.
Children's emotional and social development is an important aspect that is not neglected this being also the case for cognitive development in young children (0-2 years). For healthy emotional development, the child must possess previously acquired skills, such as self-esteem, self-confidence, curiosity, motivation, perseverance and self-control. These skills develop in the context of a balanced family, where the child develops harmoniously, the relationship between the child and the parent being an important aspect for future skills. The results of the studies carried out by Lozada and Halberstadt (2015) show that emotional competence is closely linked to social competence, this connection being conceptualized with 
the phrase "affective-social competence" (Schaffer, 2010, p.149). Self-awareness in children has the function to make children more psychologically self-conscious social actors who also possess greater insight into others.

The concept of "emotional identity" incorporates an energetic and ever changing conduct at an emotional level that presents the role of helping the child in coping and handling either pleasant or stressful situations. In the general sense "emotional identity" represents the way in which people identify themselves through emotions (Sturkenboom, 2014). The way in which children use emotions in any setting, in general, and school environment in particular, is highly informative of the way they have developed a certain mechanism that will help them in any difficulty. Emotions have an important role in helping the child be productive both socially and culturally when engaging into school and home life. When addressing the role that relations play in constructing emotions in teachers, Michalinos Zembylas (2005) he insists in the exploration of the "personal, cultural, political, and historical aspects of teacher identity formation". In this aspect we can also extrapolate this "exploration" of all aspects of child emotional development for his identity formation. Attempts in defining emotional identity formation have revealed that group/team activities play an important role in establishing certain tasks (Simion and Stan, 2019) that help children in their attempt in finding a balance between using emotions and expressing emotions.

The teacher has the important role of "designing" a vision for the purpose of elaborating on the personal and common objectives of evaluation in the classroom. The way he uses the particularities of each child in his classroom can have an impact on the outcomes of the tasks meant for evaluation. The structure of the education process was conceived (decades ago) as having only two main components: the teaching, carried out by the teacher and the learning, carried out at the level of the student, the didactic evaluation being regarded as external and subsequent to the course the teaching-learning interaction.

Children prefer having feedback for the task they perform at school or at home and they need this feedback for both correct and incorrect actions shown in a study for determining the type of corrective feedback in a computerized task (Garcia-Blanco et al., 2016) and if learning is to occur feedback is essential (Imants and Veen, 2010). Teacher's role of reflecting on student performance, work and tasks promotes professional development and will help guide the student's in the right direction towards goal fulfillment.

\section{Theoretical foundation: Wellbeing and evaluation: exercise or emotional identity}

The UE has mainly been focusing on the standardization and ratification on the new school curriculum that focuses on the child and this means that policy makers have an extra influence in creating a teaching environment that benefits the child and also the teacher. All the participants in the teaching process have a commitment in promoting wellbeing for children in the school environment and this is associated with specificities regarding functioning in physical, behavioural, social and cognitive areas. Teachers have a responsibility in creating a collaborative space for their pupils in the classroom and they have to improve on their active listening skills and acquire expertise so that they will actively and effectively respond to the diverse and challenging situations in the classroom space (Thorburn and Dey, 2016). Different limitations in one field (physical, cognitive, emotional, etc.) don't necessarily mean limitations in all areas. Focusing on developing one specific mechanism or characteristics can narrow the vision and one could focus only on determining one aspect of wellbeing when in fact the threshold was wrong to begin with. Novel situations appear all the time in the learning process and teacher have a task at hand to use all the necessary means to improve their skills such as: active listening, task managements, evaluation feedback, learning feedback, effective problem solving.

Teacher and parents have different views on the way the children should and could experience the learning and evaluation process. Different focuses means different abilities necessary from the children's developmental process. A certain level of expectations has the capacity to demand certain outcome from school performance and the set of mechanism set in motion by these expectations from the teacher's part as well as parent's tend to neglect the aspect of emotional expression. Pressures exercised on the child are felt on the emotional level with different intensity and this depends on the experience that the child has with learning and evaluation tasks. Wellbeing has an important component of a relaxed approach in task performing. Appropriate instruments used by the teacher in the evaluation process could set the starting point for a balanced outcome or burnout. Parents' satisfaction with school quality is reflected in test-based measures even 
though the wellbeing of the child is unrelated with school performance or school status (Gibbons and Silva, 2010). With the strategies well organized by the teacher and an open mind from parents' children can form an emotional identity that will help them in a better coordination and balance in concern to interactions with their peers, their teachers and their parents for better awareness of their own understandings. This in return will constitute a powerful tool when children have to transpose themselves in the evaluation mode.

The current study focuses on the perceived emotions during evaluation tasks and outcomes, subjective and objective interest in school. Research hypothesis: The systematic use of concepts specific to the socio-emotional development in the evaluation of primary school children leads to the improvement of the emotional identity and well-being in the context of the evaluation process.

\section{Research methodology}

\subsection{Participants}

In the study, 85 children $(50.6 \%$ female $)$ from one primary school in Cluj-Napoca enrolled in the $3^{\text {rd }}(19 \%)$ and $4^{\text {th }}$ grade $(66 \%)$. From the 85 students the mean age at the beginning of the study was 10.15 years $(\mathrm{SD}=.608$ months). Participation in the study was voluntary.

\subsection{Instruments}

Demographic variables were: age and gender.

\section{School-interest}

Students' school-interest regarding the forthcoming test was self-reported on a five-item scale ranging from 5 (completely disagree) to 1 (completely agree). Students indicated the extent to which they are interested in the school classes. The key item was "I am interested in school classes".

\section{Evaluation-emotions}

To assess students' evaluation-emotions students rated on a five-point scale ranging from 5 (completely disagree) to 1 (completely agree) on a questionnaire how they feel about the qualifications they receive. The key item was "If an evaluation test is easy I feel happy".

\section{Test-score-emotions}

Students' emotions after grading of tests self-reported with an open-ended question. The key item was "If I get the grade I want I feel...". The children named their emotions using a single word.
The Profile of Emotional Competence was measured with the 20-item PEC that allows assessing emotion identification, expression, understanding, regulation and use, separately for self and others' emotions. It was developed by Brasseur and Mikolajczak (2015) in order to measure intra-personal EI and inter-personal EI separately. It assessed the five core emotional competences (identification, understanding, expression, regulation and use of emotions) distinctly for one's emotions and others' emotions. The short version is not intended to provide the subscales scores, but only the factor scores (intra- and inter-personal EI) and the global score.

\section{Results}

The results of the study are presented as follows. We first present some descriptive data concerning school subjects that are favoured by the children from the school subjects that they have weekly (Figure 1). Both female and male participants have favoured mathematics among their choses.

Figure 2. What the children chose for evaluation items

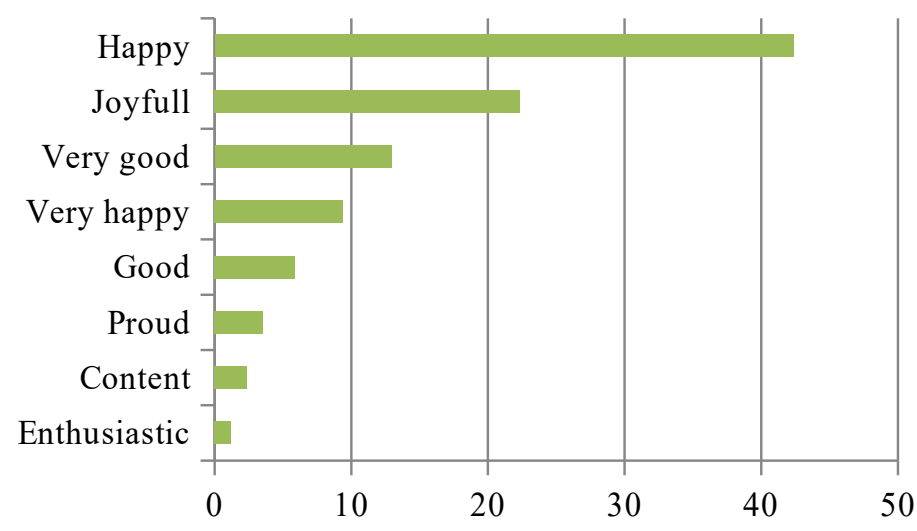

\subsection{School-interest}

We calculated means for school interest and we can see the data presented in Table 1. The results indicate that children perceive at a greater level their interest in school in comparison with their colleagues.

Table 1. Means for school interest

\begin{tabular}{lc} 
Item & Coefficient \\
\hline School-interest & M (SD)
\end{tabular}


The teacher listens to my opinion 1.81(.715)

in class

I am interested in school hours

$1.64(.079)$

My colleagues are interested in

$2.31(.833)$

school hours

\subsection{Evaluation-emotions}

The scale for evaluation for emotions during evaluation process is depicted in Table 2. There were differences among the female and male groups, but a correlation between the gender and scores did not show a significant correlation $(\mathrm{p}=.283, \mathrm{p}=.125)$.

Table 2. Means for evaluation of emotions

\begin{tabular}{lcccc} 
Gender & Mean & $\begin{array}{c}\text { During the evaluation } \\
\text { test there is a pleasant } \\
\text { atmosphere }\end{array}$ & $\begin{array}{c}\text { I am interested } \\
\text { in the grades } \mathbf{i} \\
\text { obtain }\end{array}$ & $\begin{array}{c}\text { If a test is easy I } \\
\text { feel happy: }\end{array}$ \\
\hline Female & Std. Deviation & 2,0000 & 1,3256 & 1,3721 \\
\hline Male & Mean &, 89974 &, 71451 &, 78750 \\
\hline Total & Std. Deviation & 1,7619 & 1,6190 & 1,5476 \\
& Mean & 1,12205 & 1,01097 &, 94230 \\
\hline & Std. Error of Mean & 1,8824 & 1,4706 & 1,4588 \\
\end{tabular}

\subsection{Test-score-emotions}

We aimed in finding how the participants feel if they either receive a "bad" grade (see Figure 3) or a "good" grade (see Figure 4) The inital assessment reveals that the children feels mostly either "sad" or "bad" when the grade is lower than they would "calculate" in receiving. Expectations tend to give a false hope and togheter with already present consequences they shape a rather unpleasant for the profile of the child. 
Figure 3. How children feel when they receive a grade lower than the one they expected in the evaluation test

Figure 4. How children feel when they receive a grade that they want for the evaluation test

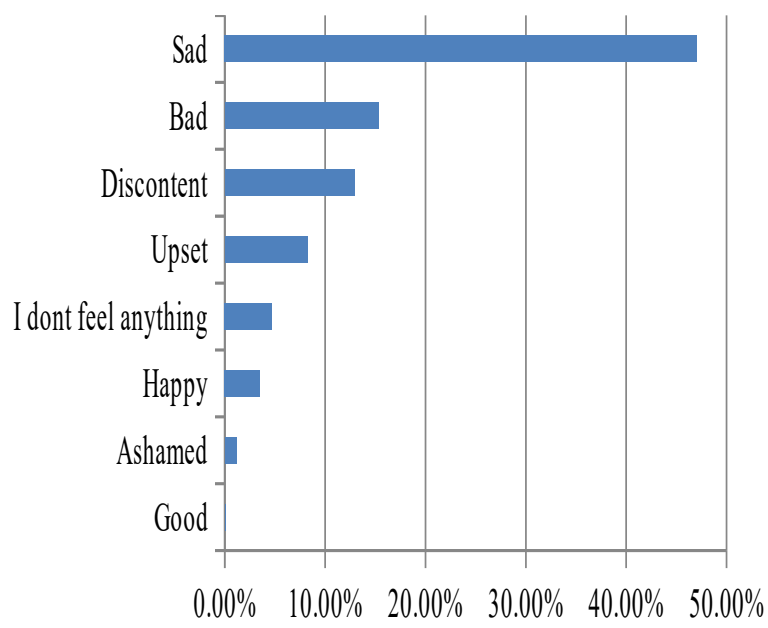

\subsection{The Profile of Emotional Competence}

We used the reduced 20-items PEC in order to measure intra-personal EI and inter-personal EI separately as total score (Table 4). Bilateral Pearson's correlations were performed on the 2 factors scores and the global score. Results (Table 5) for the intra-personal level, correlations are strong (.76 and .78). At the inter-personal level, correlations within inter-personal scales are moderate to strong (.76). For gender there is no significant correlation with either factor score or global score, there was a lower effect of age on EC for intrapersonal EC (.19)

Table 4. Means, standard deviations of the PEC subscales and factors for female and male participants $(n=85)$

\begin{tabular}{cccc} 
& Gender & Mean & Std. Deviation \\
\hline \multirow{2}{*}{ Intrapersonal EC } & Female & 3,4047 &, 605 \\
& Male & 3,3286 &, 444 \\
\hline \multirow{2}{*}{ Interpersonal EC } & Female & 3,1349 &, 520 \\
& Male & 3,0476 &, 493 \\
\hline \multirow{2}{*}{ Global score EC } & Female & 3,2698 &, 563 \\
& Male & 3,1881 &, 469 \\
\end{tabular}


Table 5. Correlations between PEC factor score and total score $(n=85)$

\begin{tabular}{|c|c|c|c|c|c|}
\hline & Age & Gender & Intrapersonal EC & Interpersonal EC & Global score EC \\
\hline Age & 1 & $.256^{* *}$ & $.193^{*}$ &, 070 &, 172 \\
\hline Gender & $.256^{* *}$ & 1 &,- 072 &,- 087 &,- 102 \\
\hline Intrapersonal EC & $.193^{*}$ &,- 072 & 1 & $.201^{*}$ & $.787^{* *}$ \\
\hline Interpersonal EC & ,070 &,- 087 & $.201^{*}$ & 1 & $.763^{* *}$ \\
\hline Global score EC & 172 &,- 102 & $.787^{* *}$ & $.763^{* *}$ & 1 \\
\hline
\end{tabular}

\section{Conclusions}

The XXI century has brought a change in the curricular paradigm and the child is the focus of the modelling of the new curriculum almost in all the educational systems. The new skills and competences of this century have been a product of the interaction with the real-life necessities and the preparation of the future adult for the challenges of the world.

The evaluation process is essential in the development of the emotional identity (EI) because the students are main actors in all the dimensions of the educational process, not only in the training process. Thus, with this vision all the actors participating in the educational process will be able to practice with meaning and active each component of the learning process met in the formal system. A major impact on primary school children's lives is the home environment and the way parents manage to provide them with a balanced environment in which the student can develop both cognitively and emotionally.

Teacher must adapt their methods and their instruments for a more dynamic assessment in evaluating and modifying cognitive functioning simultaneously through mediation and intervention. Collaboration with the students and between the students offers an opportunity for emotional and social development thus conducting towards emotional identity. Without pressure but with specific goals the teacher and the parent have the power to reinforce in the minds of the children viable criteria for self-assessment and self-realisation. Letting students compose their own items for evaluation they are made part of the learning process and together they will make sense and facilitate learning.

The main premise of the optimization of the educational process from at least two points of view: firstly because in this way it becomes possible to effectively combine the effort of the student and the teacher in the direction increase in school performance and secondly because the relationship congruence selfevaluation-evaluation transforms the student into a subject with full rights of the action educational, a subject that is thus really motivated for engaging in the endeavour permanent self-realisation.

\section{Author note:}

Anca-Georgiana Simion is a $\mathrm{PhD}$ in Education at the Department of Educational Sciences, Babeș-Bolyai University. Her main field of research is music and the social and emotional development in primary school children. She has a MA degree from Babeș-Bolyai University in Cluj-Napoca, for School counselling and psycho-pedagogical assistance and also Curricular management. Anca-Georgiana Simion has a BA of music in classical piano from the Musical Academy in ClujNapoca (2008) and a BA of education in primary school teaching from the Faculty of Psychology and Educational Science in Cluj-Napoca (2014).

Cristian Stan is habilitated Professor and Ph.D., Department of Educational Sciences, Faculty of 
Psychology and Educational Sciences (Babeş-Bolyai University, Cluj-Napoca) and Director of the Doctoral School Education, Reflection, Development. His research area covers several educational domains such as Theory of education, Theory and practice of didactic evaluation, Intercultural education, Didactic communication, etc.

\section{References}

García-Blanco, A., García-Blanco, M.D., Fernando, B., \& Perea, M. (2016). Influence of computer feedback on attentional biases to emotional faces in children. Computers in Human Behavior. 64, 881-887. doi:10.1016/ j.chb.2016.07.064.

Gibbons, S., \& Silva, O. (2011). School quality, child wellbeing and parents' satisfaction. Economics of Education Review, 30(2), 312-331. doi: 10.1016/j.econedurev.2010.11.001.

Imants, J., \& Veen, K.V. (2010). Teacher Learning as Workplace Learning. International Encyclopedia of Education, 569-574. doi: 10.1016/b978-0-08-044894-7.006576

Lozada, F. Halberstadt, A. (2015). Early Emotional Development and Cultural Variability. International Encyclopedia of the Social \& Behavioral Sciences (Second Edition). Pages 746-751. doi: 10.1016/B978-0-08-0970868.23007-9.

Simion, A., \& Stan, C. (2019). Emotional Identity Formation in Primary School Children In A Formal Context. The European Proceedings of Social \& Behavioural Sciences. Pages 322329. doi: 10.15405/epsbs.2019.06.40.

Schaffer, H.R. (2010). Introducing Child Psychology (Introducere în psihologia copilului). ASCR, Cluj-Napoca.

Sturkenboom, D. (2014). Understanding Emotional Identities The Dutch Phlegmatic Temperament as Historical Case-Study. Royal Netherlands Historical Society. e-issn: 2211-2898.

Thompson, R.A. (2007). The Development of the Person: Social Understanding, Relationships, Conscience, Self. Handbook of Child Psychology. doi: 10.1002/9780470147658.chpsy0302.

Thorburn, M., \& Dey, D. (2017). Health and wellbeing and wider achievement: An analysis of teachers' practices and learners' experiences in Scottish secondary schools. Studies in Educational Evaluation, 52, 24-34. doi: 10.1016/j.stueduc.2016.11.004.

Zembylas, M. (2005). Discursive practices, genealogies, and emotional rules: A poststructuralist view on emotion and identity in teaching. Teaching and Teacher Education, 21(8), 935-948. doi: 10.1016/j.tate.2005.06.005. 